\title{
CAESOK 16TH MIDTERM AND 8TH POSTGRADUATE CONVENTION, KOCHI
}

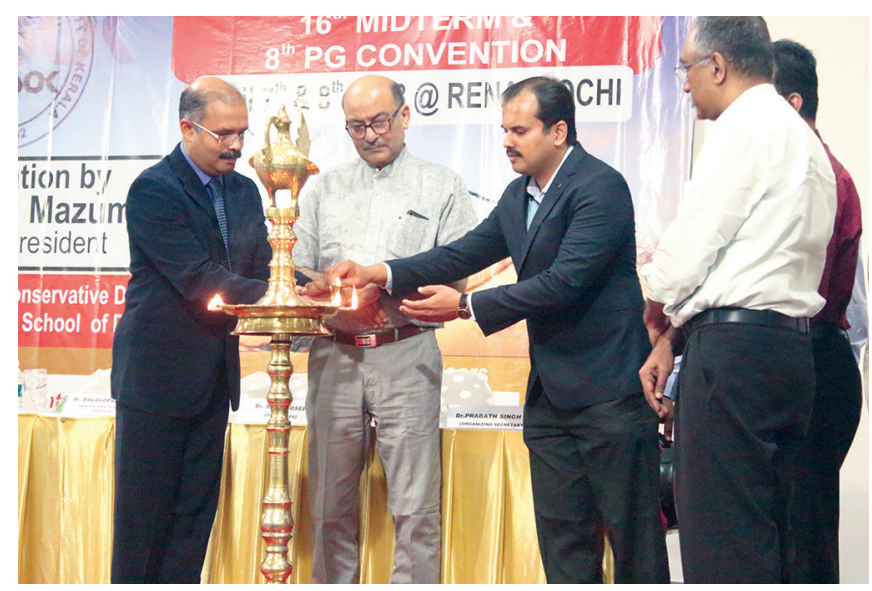

Fig. 1: Inauguration of the Conference

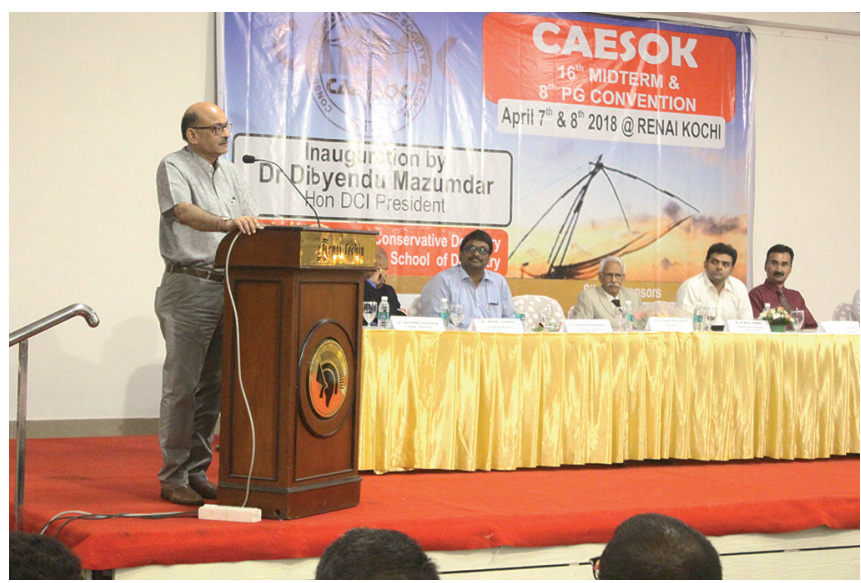

Fig. 2: Inaugural Address by the Chief Guest Dr Dibyendu Mazumder, President, Dental Council of India

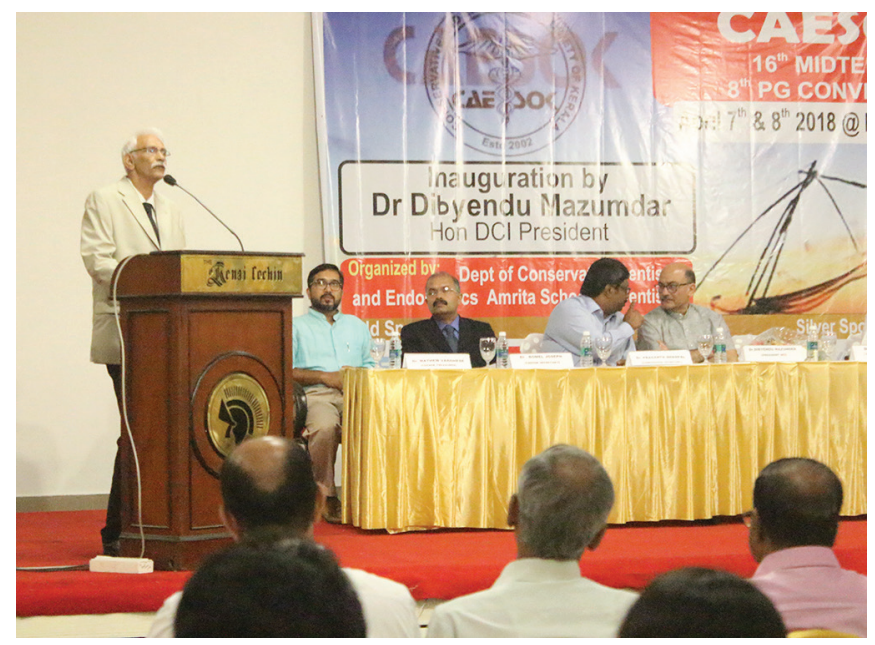

Fig. 3: Inaugural address by CAESOK's President Dr Ravi Varma

\section{Overall Best Paper and Poster Winners}

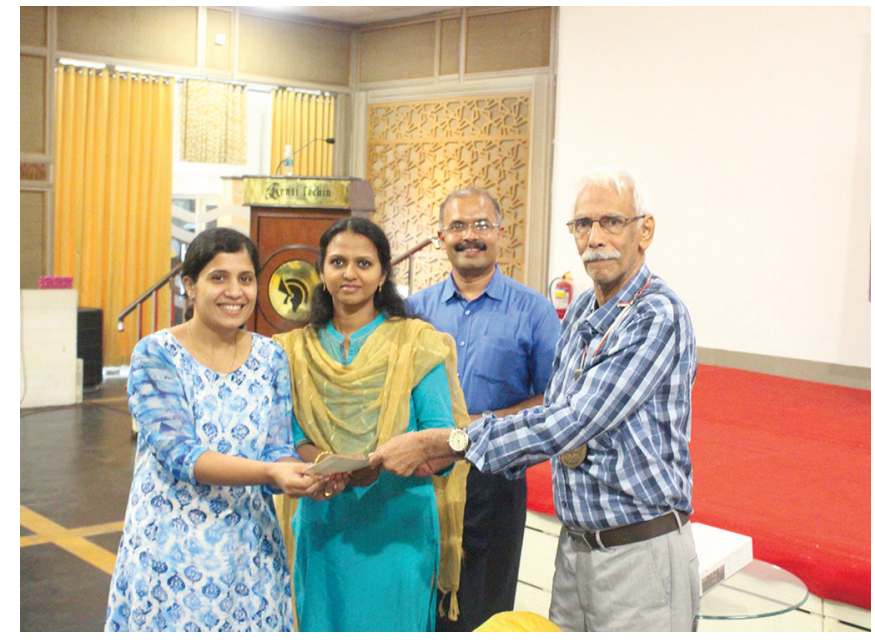

Fig. 1: Best Paper Winners

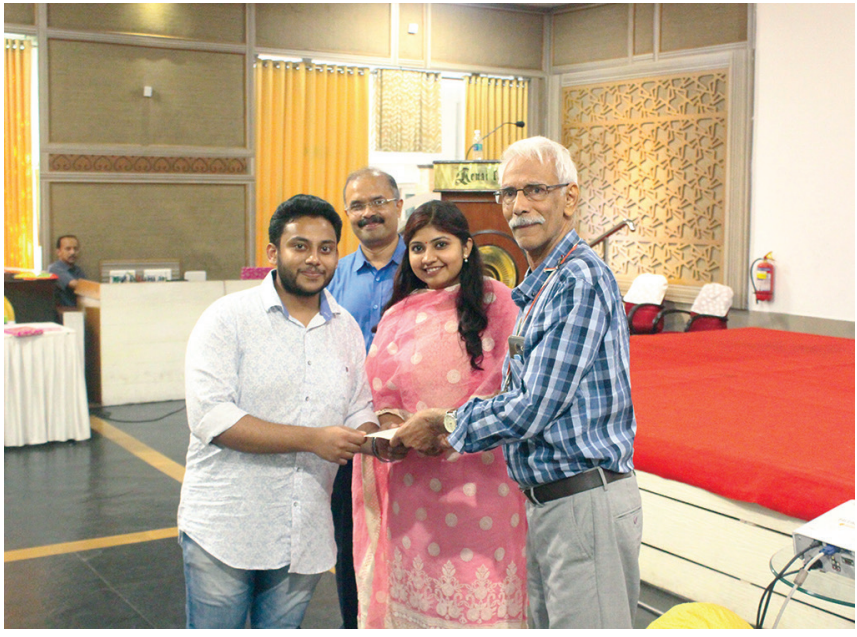

Fig. 2: Best Poster Winners 